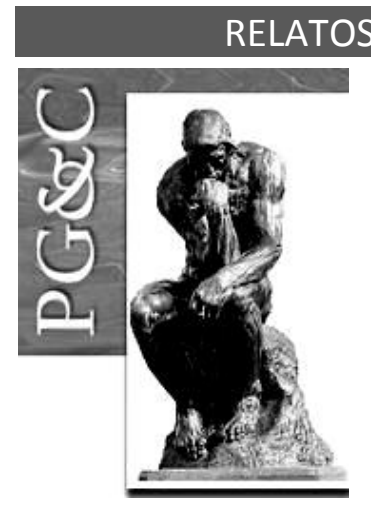

\title{
FLUXO NA GESTÃO DA INFORMAÇÃO TÉCNICA E CIENTÍFICA DO INSTITUTO FEDERAL CATARINENSE
}

\author{
Bernardete Ros Chini \\ Mestre em Ciência da Informação pela Universidade Federal de \\ Santa Catarina, Brasil. Bibliotecária do Instituto Federal Catarinense, Brasil. \\ E-mail: broschini@gmail.com \\ Úrsula Blattmann \\ Doutora em Engenharia de Produção pela Universidade Federal de \\ Santa Catarina, Brasil. Professora da Universidade Federal de \\ Santa Catarina, Brasil. \\ E-mail: ursula@ced.ufsc.br
}

\begin{abstract}
Resumo
A pesquisa objetiva analisar o fluxo de Gestão da Informação técnica e científica publicada no Instituto Federal Catarinense. Como procedimentos metodológicos, definiu-se: a pesquisa bibliográfica para compor a contextualização teórica; a pesquisa documental para categorizar o fluxo da informação; a pesquisa aplicada, pois pretende contribuir com fins práticos; o método descritivo, do tipo estudo de caso e análise documental para descrever o fluxo informacional; a abordagem qualitativa para análise das informações. Os resultados obtidos na análise documental dos relatórios anuais de gestão sobre as publicações bibliográficas foram divididos em quatro etapas, conforme o modelo de fluxo da informação de Davenport aplicado no estudo de caso: determinação das exigências de publicação registradas nos relatórios anuais de gestão da instituição; obtenção das informações das publicações que estavam no Currículo Lattes dos pesquisadores e registradas nas Agências do International Standard Book Number (ISBN) e do International Standard Serial Number (ISSN); distribuição das publicações nos catálogos do Pergamum (adotado pelo Sistema de Bibliotecas da instituição) e da Biblioteca Nacional que recebe o depósito legal; uso interno por meio de consulta local e empréstimo das publicações nas bibliotecas dos 15 campi, e externo por meio de citações no Google Acadêmico. A conclusão aponta algumas barreiras nas etapas do fluxo de gestão da informação das publicações da instituição. Espera-se contribuir nas melhorias dos processos de gestão da informação publicada desde sua exigência legal de criação até a obtenção, organização, recuperação, uso, citação e preservação da memória institucional do IFC para fins acadêmicos e administrativos (legais).
\end{abstract}

Palavras-chave: Fluxos da informação. Gestão da Informação. Instituto Federal Catarinense

\section{INFORMATION MANAGEMENT FLOW OF TECHNICAL AND SCIENTIFIC INFORMATION PUBLISHED IN THE INSTITUTO FEDERAL CATARINENSE}

\begin{abstract}
These research analyzes the information management flow of technical and scientific information published in the Instituto Federal Catarinense. It has the objectives: a) examine the literature information flow models; b) categorize the information flow management; $c$ ) identify information sources; d) discuss the information management flow information. The methodological procedures was: bibliographic research; applied aresearch, because it aims to contribute to practical purposes; descriptive method; case-study type and documentary analysis to describe the information management flow; qualitatitive approach to information analysis. The annual management reports on bibliographic publication from open data published by Instituto Federal Catarinense was choose and were divided into four stages, according to Davenport information flow model applied in these case study: Determination of the
\end{abstract}

Perspectivas em Gestão \& Conhecimento, João Pessoa, v. 8, n. 3, p. 127-149, set./dez. 2018. DOI: http://dx.doi.org/10.21714/2236-417X2018v8n3p127

http://periodicos.ufpb.br/ojs2/index.php/pgc. ISSN: 2236-417X. Publicação sob Licença 
publication requirements registered in the annual management reports of the institution; Obtaining the information of the publications by the researchers Curriculum Lattes and registered in the International Standard Book Number (ISBN) Agency and the International Standard Serial Number (ISSN); Distribution of publications in the institution library catalog and the National Library catalog that receives the legal deposit; and Internal use through local consultation and publications loans in the libraries from the 15 campuses, and through quotations in Google Scholar. The conclusion points steps of the information management flow about institution's publications. Expected contribute some improvements for the information published since its legal requirement of creation until obtaining, organizing, retrieving, using, citing and institutional memory preservation of Intituto Federal Catarinense for academic and administrative (legal) purposes.

Keywords: Information flows. Information management. Instituto Federal Catarinense.

\section{INTRODUÇÃO}

Em tempos de informação excessiva, a gestão do fluxo informacional de uma instituição educacional se torna essencial para que tenha clareza sobre o caminho que sua produção de informação técnica e científica está percorrendo, qual uso e visibilidade estão obtendo.

Concorda-se com Castells (2016, p. 494) que a sociedade está envolvida pelos fluxos de capital, de informação, de tecnologia, de interação organizacional, de imagens, sons e símbolos. E além de representar elementos da organização são a expressão dos processos da vida econômica, política e simbólica.

O fluxo da informação, conforme expõe Davenport (2001), é um processo de gerenciamento que parte da determinação de exigências dos atores envolvidos, segue para obtenção destas informações, com posterior distribuição e uso.

Estudos sobre fluxo da informação vêm ocorrendo na última década no Brasil e destaca-se Vital, Floriani e Varvakis (2010, p. 86), colocam que "a literatura consultada é unânime em afirmar que a gestão da informação baseada no fluxo de informação é um recurso estratégico fundamental para o processo de tomada de decisão".

No caso dos Institutos Federais o conhecimento gerado nas pesquisas e publicado ainda possui pouca visibilidade e uso, devido:

[...] à falta de preservação e acesso a toda a produção técnico-científica da instituição, impedindo, desta forma, o desenvolvimento de um panorama técnico-científico local, a consolidação da memória institucional e dificultando a continuidade dos trabalhos iniciados, além de não contribuir para a visibilidade da instituição perante outras instituições de educação e a sociedade. A informação científica estava de tal forma dispersa que contabilizar a produção do campus, ou do IFSP como um todo, era impossível (SANTOS et al., 2012, p. 2).

Especificamente no Instituto Federal Catarinense (IFC) observou-se a inexistência de estudos com análise sobre o fluxo de gestão da informação técnica e científica publicada e desta maneira o problema de pesquisa visa analisar como ocorre o fluxo de gestão da informação técnica e científica publicada pelo IFC.

Em busca desta resposta foram determinados o objetivo geral: Analisar o fluxo de gestão da informação técnica e científica publicada pelo Instituto Federal Catarinense. E os objetivos específicos: a) Examinar os modelos de fluxo da informação disponíveis na literatura; b) Categorizar o fluxo de gestão da informação técnica e científica do Instituto Federal Catarinense; c) Identificar as fontes de informação do fluxo de gestão da informação técnica e

Perspectivas em Gestão \& Conhecimento, João Pessoa, v. 8, n. 3, p. 127-149, set./dez. 2018. 
científicas; e d) Discutir o fluxo na gestão da informação técnica e científica do Instituto Federal Catarinense. Com a respectiva contextualização pode-se categorizar, identificar e discutir os resultados com base em modelos disponíveis na literatura, no sentido de contribuir na gestão da informação.

\title{
2 GESTÃO DA INFORMAÇÃO TÉCNICA E CIENTÍFICA
}

Colocar à disposição do usuário a informação necessária ao desenvolvimento de suas questões de pesquisa ou de trabalho é um dos papéis da gestão de informação, realizada pelos profissionais da Ciência da Informação desde os seus primórdios. Isso fica evidente na colocação de Starck, Varvakis e Silva (2013, p. 52):

A origem da gestão da informação possivelmente está associada ao desenvolvimento da disciplina, conhecida por documentação, a qual nasceu de um movimento surgido no final do século XIX e início do século $X X$, na Europa, com o objetivo de desenvolver novas técnicas para gerenciar o crescente número de documentos produzidos no período - especialmente publicações científicas e técnicas.

Um dos autores clássicos a tratar do tema é Davenport (2001, p. 12), com sua perspectiva holística na qual:

\begin{abstract}
A abordagem comumente aceita para o gerenciamento de informações investimento em novas tecnologias, e só - simplesmente não funciona. Os administradores precisam, na verdade, de uma perspectiva holística, que possa assimilar alterações repentinas no mundo dos negócios e adaptar-se às sempre mutantes realidades sociais. Essa nova abordagem, que chamo de ecologia da informação, enfatiza o ambiente da informação em sua totalidade, levando em conta os valores e as crenças empresariais sobre informação (cultura); como as pessoas realmente usam a informação e o que fazem com ela (comportamento e processos de trabalho); as armadilhas que podem interferir no intercâmbio de informações (política); e quais sistemas de informação já estão instalados apropriadamente (sim, por fim a tecnologia).
\end{abstract}

Outro autor clássico é Choo (2003, p. 403) que aborda a gestão da informação como "[...] uma rede de processos que adquire, cria, organiza, distribui e usa a informação". Sua abordagem apresenta um modelo processual de administração da informação em seis processos formando um ciclo contínuo e voltado para o conhecimento.

A gestão da informação é o alicerce para o fluxo da informação técnica científica que permite a geração de novos conhecimentos capazes de contribuir na evolução das questões de pesquisa.

Antes de abordar o fluxo é preciso tratar a tipologia da informação a ser comunicada, bem como suas formas de comunicação, considerando que uma instituição voltada para a educação trabalha com informação tanto no ensino, na pesquisa, quanto na extensão. três tipos:

A divisão aqui apresentada foi a utilizada por Costa (2016, p. 44-45), contemplando

a) produção científica: Artigos completos publicados em periódicos; Capítulos de livros publicados; Livros publicados/organizados ou edições; Resumos expandidos publicados em anais de congressos; Resumos 
publicados em anais de congressos; Trabalhos completos publicados em anais de congressos;

b) produção técnica: Apresentação de trabalhos, conferências e palestras; Curso de curta duração ministrado, especialização, extensão; Entrevistas, mesas redondas, programas e comentários na mídia; Redes sociais, websites e blogs; Textos em jornais de notícias/revistas; Trabalhos e produções técnicas;

c) produção tecnológica: Patentes e registros; Produtos tecnológicos e Programas de computador.

Todos estes tipos de informação produzida necessitam de comunicação, pois conforme Le Coadic (2004, p. 33), "o papel da comunicação consiste em assegurar o intercâmbio de informações sobre os trabalhos em andamento [...]".

Enquanto Meadows (1999) enfoca a comunicação científica definindo-a como a troca de informações entre membros da comunidade científica, incluindo atividades associadas à produção, disseminação e uso da informação, desde o momento em que o cientista concebe uma ideia para pesquisar, até que os resultados de sua pesquisa sejam aceitos como constituintes do conhecimento científico.

Nesta mesma linha, Mueller (2000, p. 21) explana que "a ampla exposição dos resultados de pesquisa ao julgamento da comunidade científica e sua aprovação por ela propicia Produção Intelectual no Ambiente Acadêmico e confiança nesses resultados".

Ainda nesse mesmo sentido, Moreno e Márdero Arellano (2005, p. 78) afirmam que "o processo interativo de discussão e aprovação pelos cientistas garante confiabilidade à pesquisa". A comunicação da informação, seja técnica ou científica, segue determinado fluxo da informação.

\subsection{Fluxos da informação}

A evolução das definições sobre os fluxos da informação revela as dinâmicas e as dimensões dos processos entre o emissor e o receptor no ciclo da informação. Inomata (2012, p. 47-49) apresenta os autores que definem fluxo de informação desde 1980 até 2011 . Onze deles abordam o fluxo da informação como um processo entre emissor e receptor (KREMER, 1980; BARRETO, 1998; DAVENPORT, 2001; MORESI, 2000; JAMIL, 2001; CHOO, 2003; LE COADIC, 2004; BEAL, 2004; STAREC, 2006; WOIDA, 2008; ALTÍSSIMO, 2009). Quatro autores trazem uma abordagem do fluxo voltada a empresas (LESCA; ALMEIDA, 1994; GATES, 1999; FORZA; SALVADOR, 2001; HIBBERD; EVATT, 2004). Outros dois autores, como Vieira (2006) e Barreto (2006), apresentam um conceito relacionado ao fluxo como sequência de eventos entre a fonte emissora e a receptora. Enquanto Garcia e Fadel (2010) e North e Presser (2011) trazem conceitos mais neutros, que podem ser utilizados por qualquer organização, porém na mesma linha de que o fluxo passa por canais de informação entre seres humanos.

Em estudo mais recente Inomata et al. (2015, p. 10) retrata o resultado de um levantamento no cenário brasileiro sobre fluxo da informação, tais como: Kremer (1980), Leitão (1985), Calazans (2006), Savi e Silva (2009), Vital, Floriani e Varvakis (2010), Rodrigues e Blattmann (2011), Dalbosco e Vieira (2011), Valentim e Teixeira (2012) e Sugahara e Vergueiro (2013).

Todos os autores citados nestas pesquisas abordam detalhes e a importância do fluxo da informação no processo de gestão para cumprir o papel principal de comunicação entre o emissor e o receptor. Alguns estão mais voltados à empresa, ou áreas, mas todos objetivam descrever o que os autores clássicos como Kremer (1980), já colocavam na década de 1980 sobre o dinamismo do processo da informação na disseminação, busca, obtenção e uso.

O fluxo da informação possui fatores e subfatores, conforme identificado por Silveira

Perspectivas em Gestão \& Conhecimento, João Pessoa, v. 8, n. 3, p. 127-149, set./dez. 2018. 
Netto (2017). Os fatores são compostos por elementos e aspectos. Os subfatores têm elementos que compõem o fluxo informacional formado por:

a) Atores: Inomata, Araújo e Varvakis, (2015, p. 221) colocam que são "todos os envolvidos no fluxo de informação, e nas atividades inerentes ao fluxo e que, de alguma forma, são responsáveis para que o fluxo ocorra";

b) Canais: Estes atores necessitam de canais para a comunicação da informação conforme Mueller (2000), o sistema global de informação técnico-científica utiliza fundamentalmente dois canais básicos de comunicação, que são apresentados no seguinte contexto: os canais formais ou baseados na literatura e os canais informais ou pessoais;

c) Fontes de informação: Estão divididas em três categorias documentais: primárias, secundárias e terciárias e segundo Cunha $(2016$, p. x), “[...] o conceito de fonte de informação ou documento é muito amplo, pois pode abranger manuscritos e publicações impressas ou eletrônicas, além de objetos, como amostra mineral, obras de arte ou peças museológicas $[\ldots]^{\prime \prime}$;

d) Tecnologia: Para Valentim e Teixeira $(2012$, p. 151) as tecnologias de informação e comunicação estão presentes nos sistemas de informação e "[..] não sobrevivem sem a alimentação de novas informações geradas por seus colaboradores e stakeholders, captadas através dos fluxos de informação;

Existem também os aspectos que influenciam o fluxo informacional como:

a) Barreiras: Para Inomata (2017, p. 49), "[...] são aspectos paralisantes ao fluxo de informação e, na ocorrência desses ruídos, as organizações devem ter mecanismos ativadores atuantes como facilitadores ao fluxo de informação";

b) Necessidades: Martínez-Silveira e Oddone (2007, p. 120) colocam que "as necessidades informacionais geralmente se originam de situações relacionadas às atividades profissionais de cada indivíduo. Mas estas necessidades não são constantes, podem ser influenciadas por vários fatores";

c) Determinantes de escolha e uso: "Se uma informação vai ser selecionada ou ignorada depende em larga medida de sua relevância para esclarecimento da questão ou solução do problema." (CHOO, 2003, p. 107);

d) Velocidade de busca: conforme Araújo (2014) são "fluxos de informação mais rápidos resultam em menor tempo de respostas para as demandas informacionais".

\subsection{Modelos de fluxo da informação}

Há diversos modelos de fluxo da informação, Inomata (2012) em seu estudo cita sete deles conforme segue, agrupados por semelhanças teóricas dos autores de cada modelo:

a) Modelos para comunicação da informação: Leitão (1985), Navarro (2000), Forza e Salvador (2001). Apresentam os canais formais e informais, os fluxos internos e externos para comunicação da informação de forma horizontal e vertical, em nível de empresa ou individual, nas dimensões ascendente, descendente ou cruzadas;

b) Modelos para gestão da informação: Lesca e Almeida (1994), Choo (2003) e Beal (2007). Tratam dos fluxos de gestão da informação divididos em diferentes etapas, mas convergindo para gerir a informação na organização;

c) Modelo cognitivo: Barreto (2006). Mostra que o fluxo ocorre em dois níveis: interno e externo a organização. No primeiro há a criação da informação e no segundo há a transferência do conteúdo para um sistema de armazenamento e recuperação da informação (I) para geração do conhecimento (K) que altera a realidade do indivíduo.

Porém quando se trata especificamente de gestão da informação, Kroeff et al. (2015, p. 56) apontam em seus estudos os autores mais citados: Davenport com 67 citações; Choo com 54 e Barreto com 38; Nonaka com 37 e Valentim com 36. O autor mais citado neste

Perspectivas em Gestão \& Conhecimento, João Pessoa, v. 8, n. 3, p. 127-149, set./dez. 2018. 
estudo Davenport (2001) aborda um modelo genérico para o fluxo de gestão da informação que está dividido em quatro etapas:

a) Determinação das exigências: essa etapa é resultado da identificação do problema informacional que a organização e seus indivíduos possuem e que necessita ser solucionado pela equipe colaborativa de profissionais da informação por meio de fontes estruturadas, não estruturadas, formais ou informais;

b) Obtenção: esta etapa deve estar alinhada à anterior e constitui um processo contínuo com estratégias para obter a informação nas mais variadas fontes para: explorar, classificar, formatar e estruturar;

c) Distribuição: nesta terceira etapa a informação começa a chegar até os interessados exigindo o processamento da gestão informacional para distribuir conforme a necessidade dos usuários, considerando a: arquitetura informacional, estrutura política e investimento tecnológico da organização;

d) Utilização: quarta e última etapa, e o motivo principal do fluxo, onde haverá o uso efetivo da informação para resolução do problema informacional existente.

Adotou-se o respectivo modelo para o estudo e são apresentados os procedimentos metodológicos desta pesquisa.

\section{PROCEDIMENTOS METODOLÓGICOS}

Os procedimentos metodológicos utilizados foram: a pesquisa bibliográfica para compor a contextualização teórica; a pesquisa documental para categorizar os materiais que ainda não receberam tratamento analítico; a pesquisa aplicada, pois pretende contribuir com fins práticos; descritiva, do tipo estudo de caso e análise documental para descrever o fluxo informacional específico; a abordagem qualitativa para coleta das informações.

Para embasamento teórico do assunto, como em toda pesquisa, conforme preconizam os autores Barros e Lehfeld (2007, p. 85), "a pesquisa bibliográfica é a que se efetua tentandose adquirir conhecimentos a partir do emprego dominante de informações advindas de material gráfico, sonoro e informatizado".

Quanto à forma de abordagem do problema, a pesquisa se configura como qualitativa, pois para Flick (2004, p. 22):

as reflexões dos pesquisadores sobre suas ações e observações de campo, suas impressões, [...] e assim por diante, tornam-se dados em si mesmos, constituindo parte da interpretação, sendo documentadas em diários de pesquisa ou em protocolos de contexto..

Pádua (2012, p. 68) explana que a pesquisa documental "é aquela realizada a partir de documentos contemporâneos ou retrospectivos, considerados cientificamente autênticos (não fraudados) [...]". E, no caso específico deste estudo, foram analisados diversos documentos advindos dos dados abertos publicados pelo IFC. (INSTITUTO FEDERAL CATARINENSE, 2017c).

O estudo de caso que, segundo Yin (2015, p. 17), “[...] é uma investigação empírica que investiga um fenômeno contemporâneo (o "caso") em profundidade e em seu contexto de mundo real, especialmente quando os limites entre o fenômeno e o contexto puderem não ser claramente evidentes." Na pesquisa delineada os Institutos Federais estão distribuídos em todas as regiões do País, sendo que cada um tem diversos campi. No caso de Santa Catarina há dois IF, o Instituto Federal de Santa Catarina - IFSC e o IFC. O corpus da pesquisa analisa a produção técnica e científica dos discentes, docentes e técnicos dos 15 campi do IFC distribuídos em diferentes regiões do estado de Santa Catarina (INSTITUTO FEDERAL CATARINENSE, 2017b).

Perspectivas em Gestão \& Conhecimento, João Pessoa, v. 8, n. 3, p. 127-149, set./dez. 2018. 
A unidade de análise desta pesquisa foi determinada com base nas publicações bibliográficas confrontando com os relatórios anuais de gestão presentes no Portal de Dados Abertos da instituição (INSTITUTO FEDERAL CATARINENSE, 2017c). Conforme explica Bardin (2011) existem as seguintes fases de análise: pré-análise; Exploração do material; Tratamento dos resultados, inferência e interpretação. No caso, além de conhecer o fluxo da informação, por meio da coleta de dados, foi efetuada a tabulação dos dados em planilhas no software Excell, possibilitando a geração de tabelas e gráficos. Na etapa de representar os fluxos utilizou-se o software Bizagi. Em seguida foi possível realizar a análise e interpretação dos dados.

Para coleta de dados foi utilizada a metodologia de pesquisa documental para categorizar os materiais que ainda não receberam tratamento analítico. $O$ estudo descritivo do tipo estudo de caso e análise documental para descrever o fluxo informacional específico do IFC com base no fluxo de Davenport (2001), dividido em quatro etapas: determinação das exigências, obtenção, distribuição e utilização. A opção pelo modelo de Davenport foi por ser o autor mais citado em estudo sobre gestão da informação, conforme estudo de Kroeff et al. (2015).

A coleta de dados inicial se deu a partir dos documentos disponíveis na página do Portal de Dados Abertos no menu de acesso à informação. Os "dados são considerados abertos quando qualquer pessoa pode livremente usá-los, reutilizá-los e redistribuí-los, estando sujeita a, no máximo, à exigência de creditar a autoria dos dados e a compartilhá-los pela mesma licença". (OPEN KNOWLEDGE BRASIL, 2016).

O período pesquisado compreende desde o ano de criação até o último relatório disponível, sendo de 2009 a 2016, o que equivale a oito anos de análise documental.

Seguindo as quatro etapas de Davenport (2001), quanto à determinação das exigências foi buscada nos relatórios anuais de gestão e nos editais, porque são dados abertos disponíveis tanto à comunidade interna, quanto à externa e, segundo o MEC, "quando os dados são produzidos, coletados ou custodiados por autoridades públicas e disponibilizados em formato aberto, considera-se que estes são dados abertos governamentais". (MINISTÉRIO DA EDUCAÇÃO, 2016).

Quanto à obtenção, foi consultado a Plataforma do Currículo Lattes, tendo em vista que se tornou um padrão nacional no registro da vida estudantes e pesquisadores do país, e é hoje adotado pela maioria das instituições de fomento, universidades e institutos de pesquisa do País. (CONSELHO NACIONAL DE DESENVOLVIMENTO CIENTíFICO E TECNOLÓGICO, 2017b).

Também se consultou o International Standard Book Number (ISBN), porque as publicações não periódicas devem obter estes registros na Agência Brasileira do ISBN, na qual a maioria das publicações é registrada no Brasil, desde 1972. O ISBN é "[...] um sistema que identifica numericamente os livros segundo o título, o autor, o país e a editora, individualizando-os inclusive por edição". (AGÊNCIA BRASILEIRA DO ISBN, 2017).

Para a etapa de Distribuição, a opção foi consultar no Pergamum/IFC por ser o sistema de gestão da informação adotado para as bibliotecas do Sistema de Bibliotecas do IFC SIBI/IFC (INSTITUTO FEDERAL CATARINENSE, 2017f), e, no SophiA (BIBLIOTECA NACIONAL, 2017), por ser o sistema de gestão da informação da Biblioteca Nacional que recebe toda publicação do País conforme a política de depósito legal. Conforme Becker e Faquetti (2015, p. 85) das "31 instituições da RFEPCT que utilizam softwares para gerenciamento de acervos multiusuários, ou seja, utilizam o mesmo sistema para todas as bibliotecas, destaca-se que o Sistema Pergamum (58\%) é utilizado na maioria das instituições [...]"

Para a etapa da Utilização foi consultado Pergamum/IFC para saber o uso interno e o Google Acadêmico para saber o uso externo. Conforme Inomata e Pintro (2012), "[...] o Google Acadêmico tem se mostrado uma excelente ferramenta também para a verificação de citação da produção científica."

Perspectivas em Gestão \& Conhecimento, João Pessoa, v. 8, n. 3, p. 127-149, set./dez. 2018. 
Para este mapeamento foram criados fluxogramas utilizando o software Bizagi modeler, versão 3.1.0.011 (BIZAGI, 2016).

\section{ANÁLISE E DISCUSSÃO DOS RESULTADOS}

A seguir são apresentados os resultados nas quatro etapas pré-determinadas e representadas na Figura 1.

Figura 1 - Fluxograma do fluxo da informação: modelo Davenport adaptado ao IFC

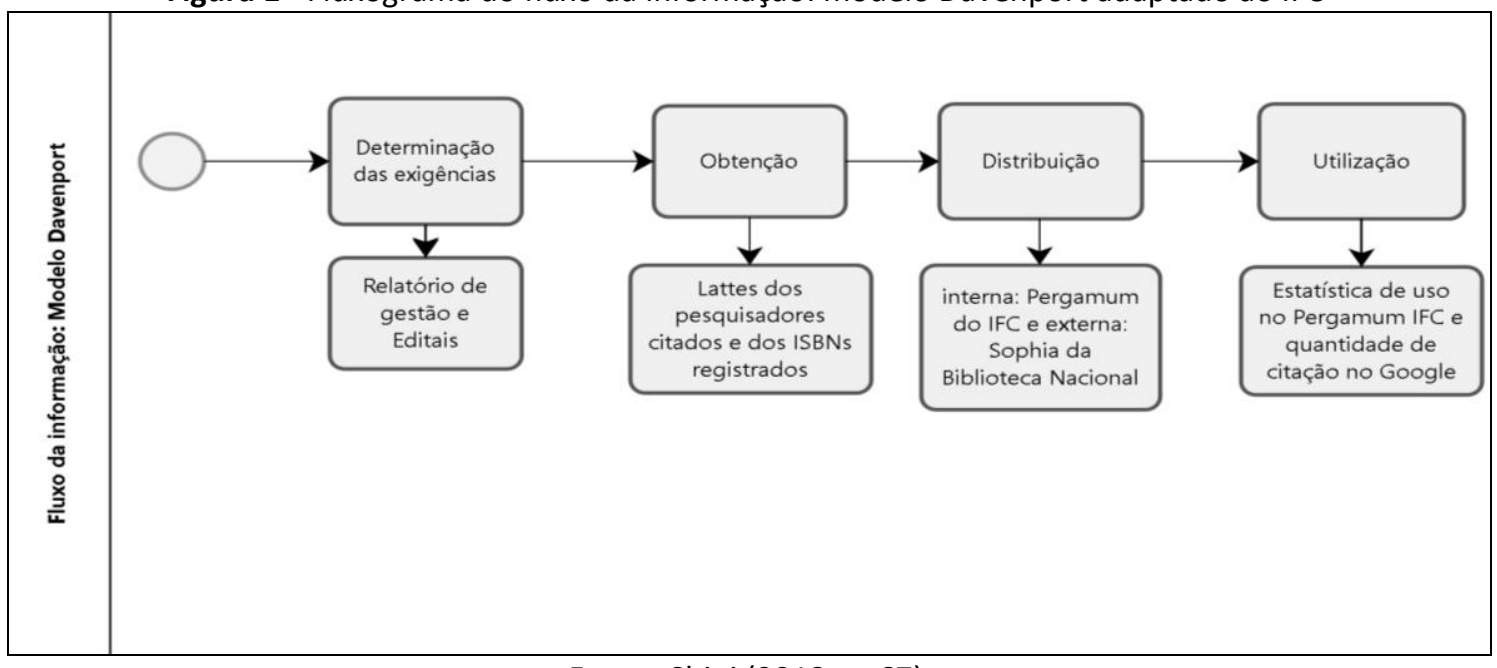

Fonte: Chini (2018, p. 67)

Estas etapas correspondem ao modelo de Davenport aplicado ao IFC. Para Valentim (2010, p. 13), "os fluxos informacionais são reflexos naturais dos ambientes ao qual pertencem, tanto em relação ao conteúdo, quanto em relação à forma".

Ao final do processo apresenta-se o fluxograma do modelo integral do fluxo de gestão da informação aplicado ao IFC (Figura 2).

Figura 2 - Fluxo de gestão da informação publicada: modelo Davenport adaptado ao IFC

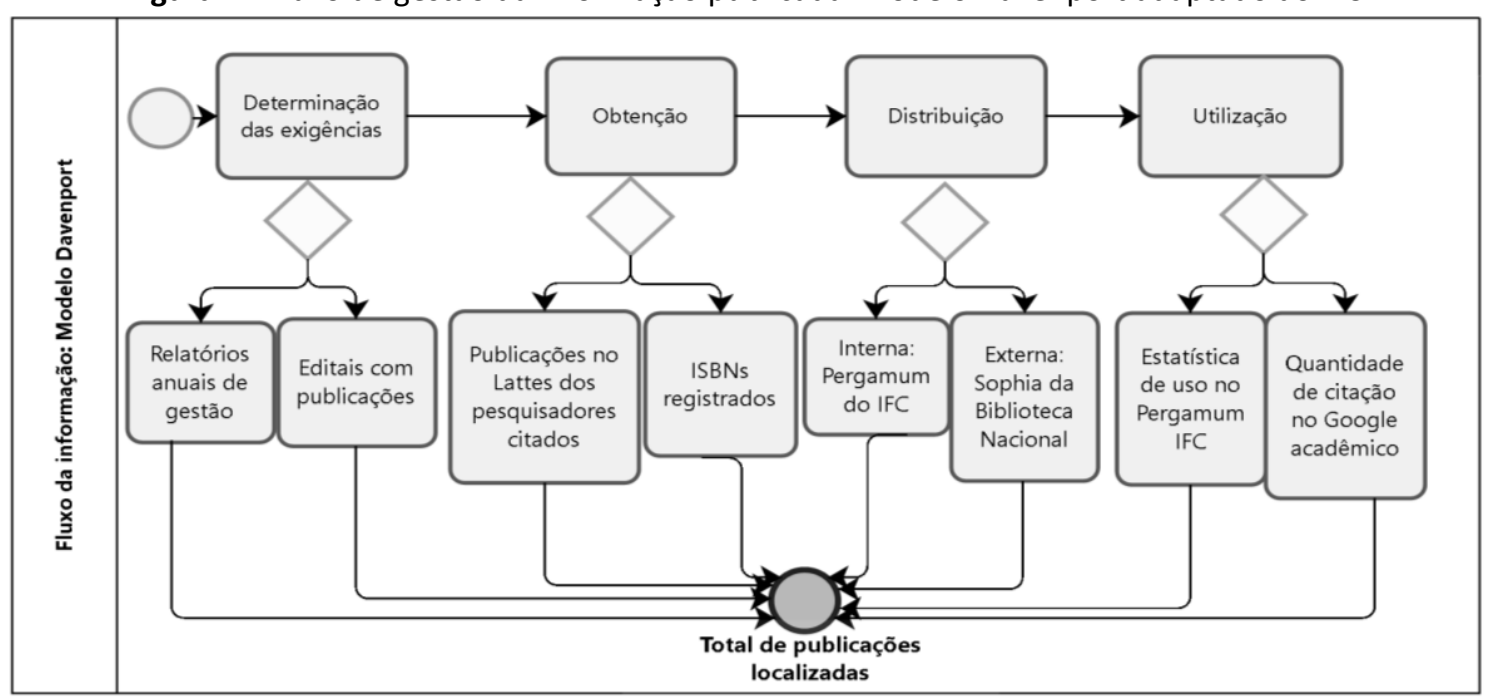

Fonte: Chini (2018, p. 105)

Perspectivas em Gestão \& Conhecimento, João Pessoa, v. 8, n. 3, p. 127-149, set./dez. 2018. 
A seguir apresenta-se o resultado com o total de publicações bibliográficas localizadas em cada etapa de análise do fluxo de gestão da informação técnica e científica produzida pelo IFC, que consta nos relatórios anuais de gestão, disponíveis no Portal de Dados abertos (INSTITUTO FEDERAL CATARINENSE, 2017c), conforme demonstra-se no Gráfico 1:

Gráfico 1 - Resultado final em cada etapa do fluxo de gestão da informação

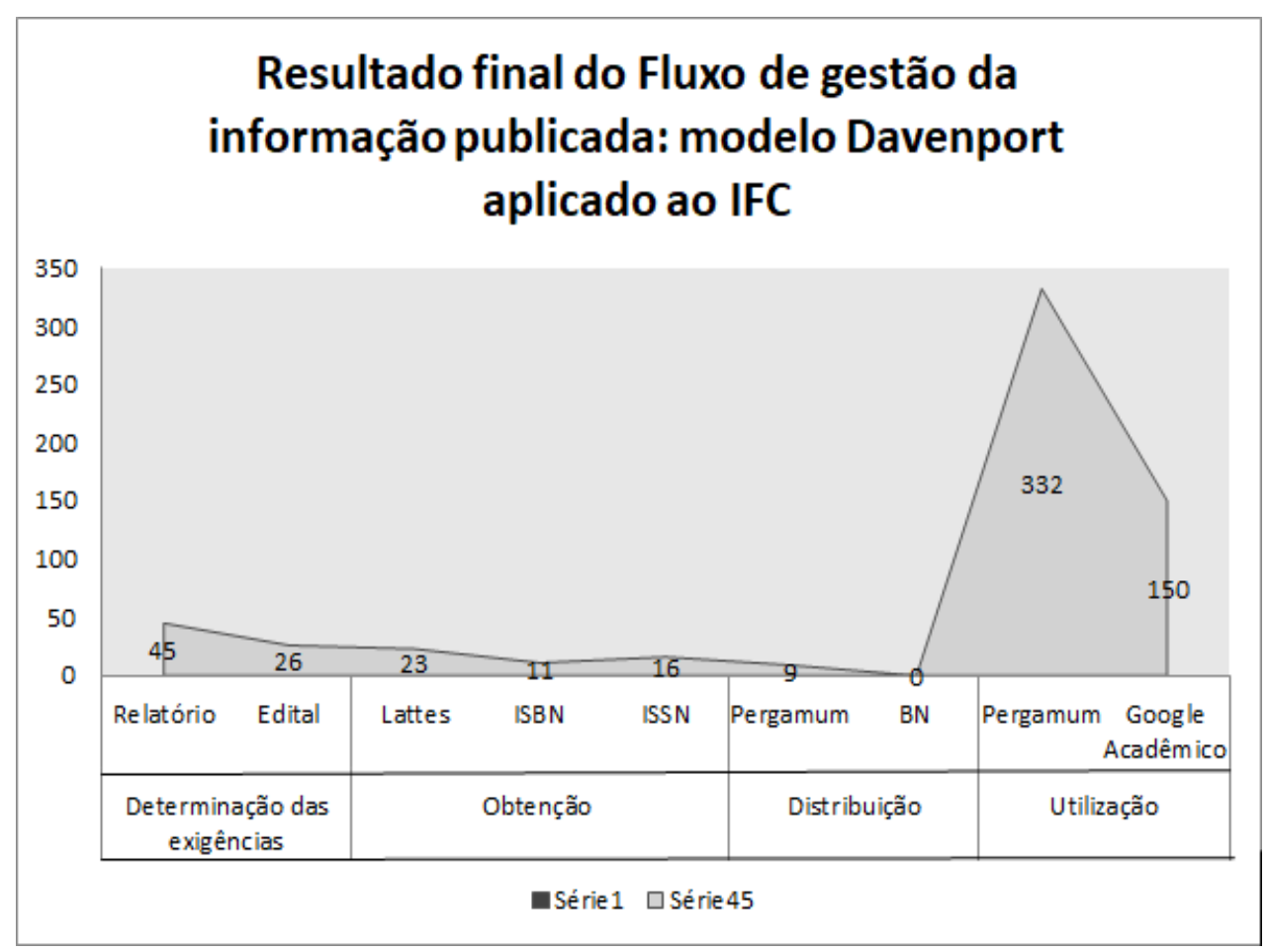

Fonte: Chini (2018, p. 105)

No Gráfico 1 vê-se que das 45 exigências de publicação bibliográfica, 26 estavam em editais do IFC, 23 no Currículo Lattes do pesquisador, 11 tinham ISBN, 16 ISSN, nenhuma estava no catálogo da Biblioteca Nacional, nove estavam no catálogo do Pergamum, adotado pelo Sistema de Bibliotecas do IFC, e foram utilizadas 332 vezes, por meio do sistema de gestão da informação publicada e foram citadas 150 vezes pelo Google Acadêmico.

Na primeira etapa do Modelo de Davenport (2001), aplicado ao IFC foram encontradas 45 determinações de exigências de algum tipo de publicação bibliográfica nas fontes documentais consultadas. Nos relatórios anuais de gestão foram utilizadas as palavras-chaves: publicação; produção científica; livro; artigo; evento; capacitação; grupo de pesquisa. Se fossem consideradas as capacitações de servidores citadas aumentaria a quantidade de exigências de publicações, porém como este resultado advindo de capacitações nos relatórios foi nulo, teve que ser desconsiderado na análise. Além disso, os editais de publicações bibliográficas saem separados por campus e pela reitoria, implicando em olhar o site de cada um. O mesmo ocorre para os grupos de pesquisa, teria que consultar o site por ano e por campus para saber o que está sendo pesquisado e depois verificar no Currículo Lattes do pesquisador para saber o que resultou em publicação e daí verificar o uso.

Aqui se percebe que as necessidades informacionais possuem informação estruturada apenas em parte, porém têm a determinação de exigências legais e regulatórias com requisitos para disponibilização da informação (DAVENPORT, 2001). Isso porque no Brasil, vários órgãos

Perspectivas em Gestão \& Conhecimento, João Pessoa, v. 8, n. 3, p. 127-149, set./dez. 2018. 
determinam exigências para disponibilidade da informação bibliográfica técnica e científica. Em relação às publicações os Institutos Federais precisam seguir orientação de alguns como:

- CAPES: exige por portaria download de teses e dissertações;

- Biblioteca Nacional: exige por lei o depósito legal das obras produzidas no Brasil;

- Agência Brasileira de ISBN: exige registro do número de ISBN de cada obra;

- Agência Brasileira de ISSN: exige registro do número de ISSN de cada obra com periodicidade definida.

Ainda na esfera federal existe a Lei da Transparência e o Decreto da Política dos Dados Abertos, que regulamentam a publicação dos dados institucionais.

No IFC também há resoluções e portarias que regulamentam a publicidade dos dados na biblioteca, nos diretórios de pesquisa, no Currículo Lattes, nas páginas e sistemas da instituição.

Portanto, há diversos órgãos, setores e pessoas envolvidas na regulamentação e publicidade das informações, mas "a informação necessária para a solução de um problema técnico muitas vezes é difícil de conseguir ou transferir, exigindo grande dispêndio de esforço, tempo e dinheiro". (CHOO, 2003, p. 240).

Ainda na primeira etapa foi verificado que destas 45 exigências de publicações encontradas nos relatórios, apenas 26 estavam contempladas em editais que resultavam em publicações bibliográficas e 19 não. Observou-se que 41 resultaram em publicações de fato, citadas nos relatórios. Ainda não aparecem nos relatórios anuais de gestão os resultados de publicações advindas dos editais de incentivo à qualificação que aconteceram após a criação das resoluções n. 09/2013 (INSTITUTO FEDERAL CATARINENSE, 2013a), a $n$. 065/2013(INSTITUTO FEDERAL CATARINENSE, 2013b) e n. 003/2014 (INSTITUTO FEDERAL CATARINENSE, 2014) pelo Conselho Superior da instituição. A partir destas resoluções foi criado um termo de compromisso e responsabilidade relativo ao afastamento integral para pós-graduação Stricto Sensu que em seu item XI, diz que o beneficiado deve "ao final do curso, apresentar cópia da dissertação de mestrado, tese de doutorado ou relatório de pósdoutorado à GCP/Campus, que deverá encaminhar à respectiva biblioteca". (INSTITUTO FEDERAL CATARINENSE, 2013c). O mesmo ocorre com a entrega de Trabalhos de Cursos (TC) dos formandos na graduação, onde são citados apenas dois TC, porém sabe-se que desde 2014 há formandos que deveriam seguir a resolução n. 54/2010 (INSTITUTO FEDERAL CATARINENSE, 2010).

Além destas exigências legais, há a questão da comunicação científica abordada por Meadows (1999, p. 7) como o "coração da ciência". Para Leite e Costa (2016, p. 68), "a ciência depende de fluxos de informação livres e desimpedidos para que possa se desenvolver efetivamente." Outra questão importante é a financeira, também citada por Meadows (1999, p. 7) "Ademais, o apoio às atividades científicas é dispendioso, e os recursos financeiros que Ihes são alocados serão desperdiçados a menos que os resultados das pesquisas sejam mostrados aos públicos pertinentes", recentemente reforçada pela COAR e a EuroCRIS na Rome Declaration sobre a importância de disponibilizar ao público o que foi financiada com seu dinheiro (ROME DECLARATION, 2011). Leite e Costa (2016, p. 68) complementam: "quanto mais rápida e completamente pesquisadores receberem a informação científica necessária às suas atividades, mais produtos científicos ele gerará a custos menores". Assim, percebe-se a importância legal e ética dos pesquisadores em publicar os resultados das pesquisas com as informações técnicas e científicas produzidas pela instituição de ensino.

$\mathrm{Na}$ segunda etapa de Obtenção da informação as 23 publicações informadas no Currículo Lattes dos autores equivalem a $70 \%$ e as publicações sem informação representam $30 \%$ do total.

Uma das barreiras a este fluxo pode ser a sobrecarga de trabalho (INOMATA, 2017), pois são muitos sistemas para entrar e informar os dados das publicações no Currículo Lattes.

Perspectivas em Gestão \& Conhecimento, João Pessoa, v. 8, n. 3, p. 127-149, set./dez. 2018. 
No IFC o pesquisador, além do Currículo Lattes alimenta as informações das publicações em mais um sistema interno, que apresenta consulta pública por docente, o Sistema Integrado de Gestão de Atividades Acadêmicas (SIGAA), criado pela Universidade Federal do Rio Grande do Norte (UFRN) e adquirido pelo IFC recentemente, apresenta o currículo do docente, mas sem um link para o Currículo Lattes (INSTITUTO FEDERAL CATARINENSE, 2017e). Lopes (2017), do Instituto Universitário de Lisboa (ISCTE-IUL), coloca que o ideal seria reduzir a quantidade de vezes que o pesquisador precisa fazer entrada de dados, facilitando a pesquisa, economizando tempo e dinheiro. Um preenchimento em local único e aproveitamento das informações pelos sistemas com integração, importação e exportação, como propõe, desde 2012, o Open Researcher and Contributor ID - ORCID ao fornecer um identificador único para pesquisadores e instituições usarem com código livre e conexões transparentes entre pesquisadores, suas publicações e organizações (OPEN RESEARCHER AND CONTRIBUTOR ID, 2017). Para Soares (2017), o ORCID é uma espécie de Currículo Lattes internacional, um currículo padronizado internacionalmente que dá visibilidade para a publicação nas principais bases de dados internacionais. Muitas já incluíram um campo ORCID para pesquisa e localização de tudo o que autor produziu, substituindo a pesquisa por autor e recuperando independente da grafia do nome, eliminando o problema de acentos, cedilhas, com uma url fixa, gratuita, irrestrita e interoperável, promovendo o intercâmbio de dados entre diversas bases.

$\mathrm{Na}$ terceira etapa do Fluxo, a de distribuição, do universo de 41 publicações, apenas nove estão cadastradas no Pergamum e 32 estão fora do sistema de gestão da informação utilizado pelas bibliotecas do IFC. Ou seja, apenas $22 \%$ das publicações citadas nos relatórios foram encontradas no sistema de gestão da informação do IFC (Pergamum). Por fim, foi constatada a ausência das informações sobre as publicações registradas nos relatórios da instituição, quando buscadas no sistema de gestão da Biblioteca Nacional, seja por ausência de depósito legal ou ainda por falta de catalogação do material recebido. Isto aponta que tanto internamente, quanto externamente há alguma barreira no depósito legal e/ou no processo de catalogação que pode estar com baixa eficiência em seu fluxo para gestão da informação recebida por doação. Assim, a distribuição fica comprometida, conforme coloca Choo (2003, p. 414): "o objetivo da distribuição da informação é promover e facilitar a partilha de informações, que é fundamental para a criação de significado, a construção de conhecimento e a tomada de decisões". Quando as obras são depositadas na Biblioteca Nacional passam pelo processo de catalogação, compondo a Bibliografia Nacional Brasileira e a instituição cumpre o que exigem as Leis $n$. 10.994, de 14 de dezembro de 2004 e n. 12.192, de 14 de janeiro de 2010, que "tem como objetivo assegurar a coleta, a guarda e a difusão da produção intelectual brasileira, visando à preservação e formação da Coleção Memória Nacional. Nele estão incluídas obras de natureza bibliográfica e musical". (BIBLIOTECA NACIONAL, 2016). Assim também deve ocorrer o depósito local, devidamente instituído em uma Política Institucional de Informação (PII), que vise assegurar a distribuição das publicação para uso e preservação da memória institucional. Ainda, conforme Choo (2003, p. 419), "a seleção e o uso das fontes para aquisição de informação precisam ser planejados e continuamente monitorados e avaliados como qualquer outro recurso vital da organização".

Na quarta e última etapa do fluxo aplicado, foi verificado a Utilização da informação internamente e externamente, sendo que dos nove documentos presentes no Pergamum, foram obtidos 332 acessos, sendo: 188 consultas no site institucional da biblioteca (http://pergamum.ifc.edu.br/pergamum/biblioteca/index.php); 118 consultas internas no espaço físico da biblioteca e 26 empréstimos. Porém, as consultas no site não significam o uso efetivo do material, pois estão sem o PDF para download, servindo para saber se o material está disponível na biblioteca. Já as consultas internas representam um uso efetivo, pois foi retirada da estante, utilizada, deixada sobre as mesas e lida pelo atendente da biblioteca antes de guardar. E os empréstimos também significam uso de fato, sendo levados para fora da

Perspectivas em Gestão \& Conhecimento, João Pessoa, v. 8, n. 3, p. 127-149, set./dez. 2018. 
biblioteca. Conforme Choo (2003, p. 417), "[...] o uso da informação é um processo social de pesquisa fluido, recíproco e repetitivo". Alguns livros dispõem de arquivo para download, mas em outros locais, por exemplo o site da editora (http://editora.ifc.edu.br/) (INSTITUTO FEDERAL CATARINENSE, 2017a). Assim, ocorre a disfunção de informação dispersa que cita Beal $(2002$, p. 35), onde "a informação está espalhada pela organização, com diversos setores produzindo, processando e emitindo informações sem nenhum tipo de integração, dificultando o acesso e o controle pelos gestores".

Externamente, foram consultadas as 41 publicações no Google Acadêmico, sendo encontradas 150 citações. Entre os tipos documentais, os anais eletrônicos foram os mais encontrados com 86 resultados, em seguida apareceu a revista do IFC com 53 resultados, também apareceram quatro artigos e três livros. O TC e o software não foram citados diretamente, mas apareceram em dois artigos sob os mesmos títulos, em dois eventos internos no mesmo mês e ano, porém, em campi distintos. Aqui nota-se novamente a disfunção de informação dispersa que cita Beal (2002, p. 35), além da disfunção de duplicidade, na qual "a falta de organização da informação acarreta a captura repetida dos mesmos dados já coletados e disponíveis". Os eventos e a revista apresentaram mais citações, demonstrando que a indexação da entidade coletiva está funcionando melhor para a visibilidade das publicações. O reconhecimento científico pelo número de citações dos artigos no Google Acadêmico ocorre porque "a citação é o meio mais comum de atribuir créditos e reconhecimento para aqueles cujos trabalhos têm contribuído para o desenvolvimento das ideias em diferentes campos" (PINTO et al. 2010, p. 204). Conforme Le Coadic (2004, p. 57), "as citações fornecem a linhagem histórica do conhecimento [...]."

Por fim o Gráfico 1 permite uma visão panorâmica dos resultados obtidos em cada etapa do modelo de Davenport (2001), aplicado ao IFC para verificação do fluxo de gestão da informação em cada sistema, a partir da análise dos dados abertos publicados pela instituição em seus relatórios anuais. Barreto (1998, p. 122) menciona que

O fluxo em si, uma sucessão de eventos, de um processo de mediação entre a geração da informação por uma fonte emissora e a aceitação da informação pela entidade receptora, realiza uma das bases conceituais que se acredita ser o cerne da ciência da informação: a geração de conhecimento no indivíduo e no seu espaço de convivência.

As fontes emissoras da informação são os autores classificados nos editais e que geram algum tipo de publicação bibliográfica ao final do processo. As entidades receptoras são o público externo e interno do IFC que buscam estas publicações, principalmente nas bibliotecas da instituição, seja online ou presencialmente. Ao final tudo fica registrado de alguma forma no sistema de gestão para fins estatísticos que ficam disponíveis ao público de forma individual e para órgãos reguladores internos e externos, como o MEC, a Coordenação de Aperfeiçoamento de Pessoal de Nível Superior (CAPES) e o Conselho Nacional de Desenvolvimento Científico e Tecnológico (CNPq), na forma de relatórios utilizados pela instituição. Davenport (2001, p. 174), coloca que se o foco for colocado na necessidade e na satisfação dos usuários, a gestão da informação se tornará mais efetiva.

Leite e Costa (2016, p. 68), concluem em seus estudos quando a rapidez da comunicação ocorre de maneira adequada e eficiente influencia diretamente o desempenho dos institutos de pesquisa. Portanto, o Instituto Federal Catarinense pode ser considerado um dos atores com a principal função a geração de novos conhecimentos técnicos e científicos.

O mapeamento do fluxo mostra o movimento que a informação percorre dentro da organização e aponta as barreiras existentes.

Perspectivas em Gestão \& Conhecimento, João Pessoa, v. 8, n. 3, p. 127-149, set./dez. 2018. 


\section{CONCLUSÕES}

O objetivo geral da pesquisa em relato consistia em analisar o fluxo de gestão da informação técnica e científica publicada pelo Instituto Federal Catarinense que foi alcançado a partir da análise de uma amostragem dos dados abertos disponíveis no portal da instituição, os relatórios anuais de gestão. Os mesmos foram escolhidos por tratarem de dados sobre a gestão da instituição, ano a ano, cumprindo as normas dos órgãos de Controle Interno e Externo como Prestação de Contas Anual a que a Unidade está obrigada nos termos do art. $\mathrm{n}$. 70 da Constituição Federal, elaborado de acordo com o disposto nas Resoluções, Instruções Normativas, Decisões Normativas e Portarias do Tribunal de Contas da União. Foram analisados os relatórios de 2009 a 2016, contabilizando oito anos de análise, contemplando desde a criação do IFC até o último relatório divulgado pela instituição.

A partir destes relatórios anuais de gestão, os objetivos específicos de: categorizar o fluxo de gestão da informação técnica e científica do Instituto Federal Catarinense; identificar as fontes de informação do fluxo de gestão da informação técnica e científicas e discutir o fluxo na gestão da informação técnica e científica do Instituto Federal Catarinense foram sendo alcançados.

Para dar sustentação à análise, foram examinados os modelos de fluxo da informação disponíveis na literatura, por meio de pesquisa bibliográfica no Portal CAPES, em páginas web, além de livros e anais de eventos, cumprindo o primeiro objetivo específico. Dos diversos modelos encontrados nos estudos e revisões de literatura o mais citado e utilizado é o de Davenport (2001). A partir daí foram coletados os dados dos relatórios e categorizados dentro do modelo de fluxo para gestão da informação, seguindo as quatro etapas propostas pelo autor: Determinação das exigências, Obtenção, Distribuição e Utilização.

Para atender ao segundo objetivo específico apresentam-se os detalhes da categorização do fluxo da gestão da informação.

Para a determinação das exigências foram realizadas buscas nos relatórios e editais por serem dados abertos da instituição, estando disponíveis a qualquer pessoa sua consulta e uso, mediante citação. Além disso, cumprem as exigências legais do Tribunal de Contas da União e de órgãos internos sobre a prestação de contas à sociedade.

$\mathrm{Na}$ etapa de obtenção da informação publicada pelo IFC foram consultados: o Currículo Lattes dos pesquisadores citados nos documentos consultados, para saber se os mesmos haviam informado sua produção científica; e a Agência Brasileira do ISBN para saber se havia cumprido a exigência legal de registro que cada publicação não periódica tem que cumprir no Brasil. A agência do International Standard Serial Number (ISSN) não foi necessária à consulta, pois a instituição possui apenas um periódico e já estava com a informação de número normalizado.

Durante a etapa da distribuição foi consultado se o material publicado havia sido distribuído internamente para as bibliotecas do Sistema de Bibliotecas do IFC - SIBI/IFC e externamente para a Biblioteca Nacional, cumprindo a Lei de Depósito Legal, a qual todos os autores têm que cumprir no Brasil, enviando um exemplar, a fim de compor a bibliografia nacional, preservando a memória intelectual do País.

$\mathrm{Na}$ etapa da utilização foram consultados internamente dados estatísticos de uso no sistema interno de gestão da informação utilizado pelas bibliotecas do IFC, o Pergamum e externamente, citações das publicações no Google Acadêmico, pois é uma plataforma que indexa grande parte das publicações.

Esta categorização do fluxo nas quatro etapas de Davenport permitiu cumprir o terceiro objetivo específico de identificar as fontes de informação do fluxo de gestão da informação técnica e científica do IFC, sendo que as registradas nos relatórios são somente as formais, obtidas por meio de publicações com os tipos documentais: artigo, livro, anais 
eletrônicos, revista, software e trabalho de curso. Nos relatórios anuais de gestão foram encontradas e referenciadas as seguintes fontes de informação: 16 artigos, 13 livros, sete anais eletrônicos, dois softwares, dois trabalhos de curso e uma (1) revista.

Além das fontes, foram identificados vários detalhes das publicações como suporte, por exemplo. Das 41 publicações, 22 estão na internet, oito em papel, cinco em papel e internet, quatro não foram identificadas e uma (1) em e-book, mostrando a evolução para o meio digital.

O quarto e último objetivo específico de discutir o fluxo na gestão da informação técnica e científica do Instituto Federal Catarinense foi possibilitado a partir dos dados identificados no Gráfico 3, no qual obteve-se o resultado final em cada etapa de análise sob o modelo de Davenport (2001). Das 45 exigências de publicação determinadas nos relatórios anuais de gestão, apenas 26 estavam em editais, 23 no Currículo Lattes, 11 tinham ISSN, 16 tinham ISBN, nove estavam registradas no Pergamum/IFC e nenhuma na Biblioteca Nacional. Assim, foi possível saber que das 45 exigências, apenas 41 eram publicações de fato e apenas 26 estavam contempladas em editais. Porém, futuros estudos podem ser feitos verificando outros dados da instituição para saber se existem mais publicações que por algum motivo não apareceram nestes relatórios de gestão.

Quanto à obtenção de informações externas sobre as publicações, das 41 publicações, 23 foram encontradas no Currículo Lattes dos pesquisadores citados nos relatórios, mostrando que $70 \%$ das publicações estavam informadas até o momento do estudo e $30 \%$ ainda não estavam. Uma das barreiras informacionais detectadas aqui foi a da sobrecarga de trabalho, pois identificou-se que o pesquisador tem que alimentar os dados em muitos sistemas. No IFC, o pesquisador alimenta no Currículo Lattes e no Sistema Integrado de Gestão de Atividades Acadêmicas - SIGAA. Em algumas instituições isso ocorre apenas uma vez por meio do ORCID, um identificador individual que alimenta uma espécie de Currículo Lattes internacional.

Quanto à obtenção de registro dos números normalizados no país, 11 tinham ISSN e 16 tinham ISBN, totalizando 27 publicações com registro e $14 \mathrm{sem}$. Destaca-se que o processo de registro das publicações ocorre com algum ruído, que precisa ser melhor identificado.

Sobre a distribuição das 41 publicações identificadas, nove foram encontradas registradas no catálogo do Pergamum/IFC e nenhuma no catálogo da Biblioteca Nacional. Aqui os dados mostram que a informação até o momento desta pesquisa apresenta algum gap, ruído ou barreira no processo de distribuição via Lei Depósito Legal, no âmbito externo ou via Política de Institucional de Informação no ambiente interno, ou ainda, no setor de catalogação das bibliotecas responsáveis, caso tenham recebido os depósitos legais.

Quanto ao uso, às publicações foram utilizadas 332 vezes por meio dos dados estatísticos registrados no sistema de gestão da informação do IFC, Pergamum e foram citadas 150 vezes, conforme busca realizada no Google Acadêmico. Considerando que apenas nove publicações foram encontradas no Pergamum, pode-se dizer que obtiveram bastante uso. Porém, no Google Acadêmico, que registra o conhecimento e divulga em toda a web, o ideal seriam mais resultados. A explicação para maior uso interno pode ser devido às publicações atenderem áreas de interesse deste público específico e porque são mais divulgadas pelos autores internamente. Davenport (2001, p. 195) coloca que "embora seja difícil avaliar o uso da uma informação individual, é relativamente fácil estimar esse uso [...]".

Assim, conclui-se que todos os objetivos propostos foram alcançados, revelando o fluxo de gestão da informação técnica e científica publicada pelo Instituto Federal Catarinense, tanto nos pontos com êxito, quanto nos pontos com barreiras a serem resolvidas.

Portanto, ao final do estudo podem-se realizar as seguintes recomendações para outros estudos ou uso na resolução de barreiras identificadas na gestão do fluxo da informação:

Perspectivas em Gestão \& Conhecimento, João Pessoa, v. 8, n. 3, p. 127-149, set./dez. 2018. 
a) Acompanhar os editais publicados separadamente por campus e pela reitoria, para facilitar a verificação do atendimento dos editais e confrontar as publicações (comunicações, divulgações e listagens dos sujeitos contemplados);

b) Informações dos grupos de pesquisa ainda são publicadas separadamente, e dificulta a visibilidade do conjunto. No caso, necessita-se ainda consultar o site por ano e por campus para saber o que está sendo pesquisado e depois verificar no Currículo Lattes do pesquisador para saber o que resultou em publicação e, em seguida, verificar o acesso. No caso recomenda-se normalizar procedimentos para depósito local e depósito legal, com informações centralizadas e disponibilizar com uma política institucional de informação (interna realizada pelo depósito legal e explicitada nos editais);

c) As informações pulverizadas dificultam a organização e análise das publicações, pois com o uso de elementos bibliográficos padronizados, por exemplo, em adotar as Normas técnicas da Associação Brasileira de Normas Técnicas (ABNT) seja para citação e ou referências facilitaria a obtenção das informações nos relatórios e editais;

d) A internet facilita a visibilidade da informação, mas paralelamente apresenta informações dispersas, espalhadas em vários links dificultando o acesso, recuperação, controle e uso. Recomenda-se o uso do controle bibliográfico universal, desde o depósito legal nacional e local, isto é, na Biblioteca Nacional e nas Bibliotecas do Sistema do Instituto Federal Catarinense; o uso do International Standard Name Identifier - ISO 27729 aplicado para a identificação internacional de nomes de autoridades, por exemplo, o ORCID, o Digital Object Identifier (DOI), seja institucional e individual, inclusive a adoção de ISSN e ISBN, apoio no registro das informações na Plataforma do Currículo Lattes, pois podem servir como instrumento de identificação e visibilidade internacional padronizada;

e) Com uma política de informação institucional poderá ser incrementada a visibilidade da produção, do acesso e do uso da informação para evitar a duplicidade de informação incompleta e fortalecer a instituição. A política favorece a compreensão do fluxo da informação, seja desde o momento de incentivos de fomento para a pesquisa via editais, até o ciclo final a publicação e seu depósito legal. Assim, o leitor segue a ser autor e completa o ciclo como Lautor.

Espera-se que o estudo desperte a realização da política da informação institucional e que outros estudos possam fortalecer aspectos apontados. A soma de estudos aplicados a esta realidade viabiliza esforços para a melhoria no seu fluxo da informação.

Almeja-se que a presente pesquisa contribua para a Ciência da Informação por meio da análise elaborada no sentido de que possa servir para outras instituições de ensino técnico e científico no atendimento à demanda de fluxo de gestão da informação e assim, fortalecer aspectos da gestão da informação aproximando a teoria da práxis.

\section{AGRADECIMENTOS}

Agradecemos ao Instituto Federal Catarinense a possibilidade de realizar a coleta e o uso dos dados abertos para elaboração da investigação realizada no âmbito do Programa de Pós-Graduação em Ciência da Informação na Universidade Federal de Santa Catarina.

\section{REFERÊNCIAS}

AGÊNCIA BRASILEIRA DO ISBN. 0 que é o ISBN. Disponível em: http://www.isbn.bn.br/website/. Acesso em: 08 out. 2017.

ALTíSSIMO, T. L. Cultura organizacional, fluxo de informações e gestão do conhecimento: um

Perspectivas em Gestão \& Conhecimento, João Pessoa, v. 8, n. 3, p. 127-149, set./dez. 2018. 
estudo de caso. 2009. 167 f. Dissertação (Mestrado em Ciência da Informação) - Programa de Pós-Graduação em Ciência da Informação, Universidade Federal de Santa Catarina, Florianópolis, 2009.

ARAÚJO, W. C. O. O fluxo de informação em projetos de inovação: estudo em três organizações. 2014. 144 f. Dissertação (Mestrado em Ciência da Informação) - Programa de Pós-Graduação em Ciência da Informação, Universidade Federal de Santa Catarina, Florianópolis, 2014. Disponível em: http://www.bu.ufsc.br/teses/PCIN0103-D.pdf. Acesso em: 06 set. 2017.

ARAÚJO, W. C. O.; SILVA, E. L. da; VARVAKIS, G. Fluxos de informação em projetos de inovação: estudo em três organizações. Perspectivas em Ciência da Informação, Belo Horizonte, v. 22, n. 1, p. 57-79, mar. 2017.2 Disponível em: http://portaldeperiodicos.eci.ufmg.br/index.php/pci/article/view/2601. Acesso em: 26 set. 2017.

BARDIN, L. Análise de conteúdo. São Paulo: Edições 70, 2011.

BARRETO, A. de A. A condição da informação. In: STAREC, C.; GOMES, E. B. P.; CHAVES, J. B. L. (Org.). Gestão estratégica da informação e inteligência competitiva. São Paulo: Saraiva, 2006.

BARRETO, A. A. Mudança estrutural no fluxo do conhecimento: a comunicação eletrônica. Ciência da Informação, Brasília, DF, v. 27, n. 2, p. 122-127, maio/ago. 1998.

BARROS, A. J. da S.; LEHFELD, N. A. de S. Fundamentos de metodologia científica. 3. ed. São Paulo, SP: Pearson, 2007. 158 p.

BEAL, A. Gestão estratégica da informação: como transformar a informação e a tecnologia da informação em fatores de crescimento e de alto desempenho nas organizações. São Paulo: Atlas, 2004. $137 \mathrm{p}$.

BECKER, C. da R. F.; FAQUETI, M. F. Panorama das bibliotecas da rede federal de educação profissional, científica e tecnológica: um olhar sobre a gestão. Blumenau: IFC, 2015. 108 p. Disponível em: http://editora.ifc.edu.br/wp-content/uploads/sites/33/2017/06/Panoramadas-bibliotecas-da-Rede-Federal-de-Educa\%C3\%A7\%C3\%A3o-Profissional-Cient\%C3\%ADfica-eTecnol\%C3\%B3gica-um-olhar-sobre-a-gest\%C3\%A3o..pdf. Acesso em: 8 jan. 2017.

BIBLIOTECA NACIONAL. Acervo. 2017. Disponível em: http://acervo.bn.br/sophia web/index.html. Acesso em: 15 jul. 2017.

BIBLIOTECA NACIONAL. Depósito legal. 2016. Disponível em: https://www.bn.gov.br/sobre-bn/deposito-legal. Acesso em: 15 jul. 2017.

BIZAGI. Bizagi BPMN Modeler. 2016. Disponível em: https://www.bizagi.com/pt/produtos/bpm-suite/modeler. Acesso em: 8 dez. 2017.

CALAZANS, A. T. S. Conceitos e uso da informação organizacional e informação estratégica. Transinformação [online], v. 18, n. 1, p.63-70, 2006. 
CASTELLS, M. A sociedade em rede. 17. ed. São Paulo: Paz e Terra, 2016. 629 p. (A era da informação; economia, sociedade e cultura, v. 1).

CHINI, B. R. Fluxo na gestão da informação técnica e científica do Instituto Federal Catarinense. 2018. 161 f. Dissertação (Mestrado em Ciência da Informação) - Universidade Federal de Santa Catarina, Florianópolis, 2018.

CHOO, C. W. A organização do conhecimento: como as organizações usam a informação para criar significado, construir conhecimento e tomar decisões. São Paulo: Senac, 2003. 425 p.

CIANCONI, R. de B. Gestão do conhecimento: visão de indivíduos e organizações no Brasil. 2003. 287 f. Tese (Doutorado em Ciência da Informação) - Instituto Brasileiro de Informação em Ciência e Tecnologia, Universidade Federal do Rio de Janeiro, Rio de Janeiro, 2003.

CONSELHO NACIONAL DE DESENVOLVIMENTO CIENTÍFICO E TECNOLÓGICO (CNPq). Sobre a plataforma Lattes. 2017b. Disponível em: http://lattes.cnpq.br/. Acesso em: 01 mar. 2017.

COSTA, H. Institutos Nacionais de Ciência e Tecnologia da área de Agrárias: estudo das produções científicas, técnicas e tecnológicas. 2016. 527f. Dissertação (Mestrado em Ciência da Informação) - Universidade Federal de Santa Catarina, Florianópolis, 2016.

CUNHA, I. B. de A.; PEREIRA, F. C. M.; NEVES, J. T. de R. Análise do fluxo informacional presente em uma empresa do segmento de serviços de valor agregado (SVA). Perspectivas em Ciência da Informação, Belo Horizonte, v. 20, n. 4, p. 107-128, dez. 2015. Disponível em: http://www.scielo.br/scielo.php?script=sci arttext\&pid=S1413-

99362015000400107\&lng=en\&nrm=iso. Acesso em: 26 nov. 2018.

CUNHA, M. B. da. Para saber mais: fontes de informação em ciência e tecnologia. 2. ed. Brasília: Briquet de Lemos/Livros, 2016. 235 p.

DALBOSCO, V.; VIEIRA, A. F. G. Mediação tecnológica da informação no parlamento: estudo de uma assembleia legislativa no contexto brasileiro. Informação \& Sociedade: estudos, v. 21, n. 1, $2011 . \quad$ Disponível em: http://www.ies.ufpb.br/ojs/index.php/ies/article/viewFile/10332/7000. Acesso em: 26 ago. 2017.

DAVENPORT, T. H. Ecologia da informação: por que só a tecnologia não basta para o sucesso na era da informação. São Paulo: Futura, 2001. 316 p.

FERREIRA, T. E. de L. R; PERUCCHI, V. Gestão e o fluxo da informação nas organizações: um ensaio a partir da percepção de autores contemporâneos. Revista ACB, Florianópolis, v. 16, n. 2, p. 446-463, dez. 2011. Disponível em: https://revista.acbsc.org.br/racb/article/view/781. Acesso em: 12 jul. 2017.

FLICK, U. Introdução à metodologia de pesquisa: um guia para iniciantes. Porto Alegre: Penso, 2013. 256 p.

FORESTI, F. O uso de dispositivos móveis entre os estudantes de pós-graduação da Universidade Federal de Santa Catarina: os novos fluxos de informação. 2016. 304 p. Dissertação (Mestrado em Ciência da Informação) - Programa de Pós-Graduação em Ciência da

Perspectivas em Gestão \& Conhecimento, João Pessoa, v. 8, n. 3, p. 127-149, set./dez. 2018. 
Informação, Universidade Federal de Santa Catarina, Florianópolis, 2016. Disponível em: http://www.bu.ufsc.br/teses/PCIN0138-D.pdf. Acesso em: 02 jun. 2017.

FORZA, C.; SALVADOR, F. Information flow for high-performance manufacturing. International Journal of Production Economics, Amsterdam, v. 70, n. 1, p. 21-26, mar. 2001. Disponível em: https://www.sciencedirect.com/science/article/pii/S0925527300000384. Acesso em: 02 ago. 2017.

GATES, B. A empresa na velocidade do pensamento. São Paulo: Companhia das Letras, 1999.

GARCIA, R.; FADEL, B. Cultura organizacional e as interferências nos fluxos informacionais. In: VALENTIM, M. (Org.). Gestão, mediação e uso da informação. São Paulo: Cultura Acadêmica, 2010.

HIBBERD, B. J.; EVATT, A. Mapping information flows: a practical guide. Information management journal, v. 38, n. 1, p. 58-64, jan./fev. 2004. Disponível em: http://www.freepatentsonline.com/article/Information-

ManagementJournal/112859578.html. Acesso em: 13 ago. 2017.

INOMATA, D. O., et al. Análise da produção científica brasileira sobre fluxos de informação. Biblios: Revista electrónica de bibliotecología, archivología y museología, n. 59, p. 1-17, 2015.

INOMATA, D. O. O fluxo da informação tecnológica: uma análise no processo de desenvolvimento de produtos biotecnológicos. Florianópolis, 2012. 282 f. Dissertação (Mestrado em Ciência da Informação) - Programa de Pós-Graduação em Ciência da Informação, Universidade Federal de Santa Catarina, Florianópolis, 2012. Disponível em: http://www.bu.ufsc.br/teses/PCINO080-D.pdf. Acesso em: 10 jun. 2017.

INOMATA, D. O. Redes colaborativas em ambientes de inovação: uma análise dos fluxos de informação. 2017. 421 f. Tese (Doutorado em Ciência da Informação) Programa de PósGraduação em Ciência da Informação, Universidade Federal de Santa Catarina, Florianópolis, 2017. Disponível em: http://www.bu.ufsc.br/teses/PCIN0163-T.pdf. Acesso em: 10 jan. 2018.

INOMATA, D. O.; ARAÚJO, W. C. O.; VARVAKIS, G. Fluxos de informação na perspectiva organizacional. Informação \& Informação, Londrina, v. 20, n. 3, p. 203-228, dez. 2015. Disponível em: http://www.uel.br/revistas/uel/index.php/informacao/article/view/18209. Acesso em: 28 jun. 2017.

INOMATA, D. O.; PINTRO, S. Portais como ambientes de interação para inovação na sociedade do conhecimento. Biblios: Revista de Bibliotecología y Ciencias de la Información, n. 47, p. 129, 2012.

INSTITUTO FEDERAL CATARINENSE (IFC). Editora IFC. 2017a. disponível em: http://editora.ifc.edu.br/. Acesso em: 13 jun. 2017.

INSTITUTO FEDERAL CATARINENSE (IFC). Nossos campi. 2017b. Disponível em: http://ifc.edu.br/nossos-campus/. Acesso em: 03 mar. 2017.

INSTITUTO FEDERAL CATARINENSE (IFC). Portal de Dados Abertos do Instituto Federal Catarinense. 2017c. Disponível em: http://dadosabertos.ifc.edu.br/. Acesso em: 15 mar. 2017. 
INSTITUTO FEDERAL CATARINENSE (IFC). Resolução n. 054 CONSUPER/2010. Dispõe sobre o regulamento para elaboração o Trabalho de Curso (TC) dos Cursos Superiores do Instituto Federal Catarinense. 2010. Disponível em: http://consuper.ifc.edu.br/wpcontent/uploads/sites/14/2014/07/RESOLU\%C3\%87\% C3\%830-AD-REFERENDUM-054-2010Regulamento-Trablho-de-Curso-Superiores.pdf. Acesso em: 03 out. 2017.

INSTITUTO FEDERAL CATARINENSE (IFC). Resolução n. 009 CONSUPER/2013. Aprova as normas de afastamento para ações de capacitação e para licença capacitação, dos servidores Docentes e Técnico-Administrativos do Instituto Federal Catarinense. 2013a. Disponível em: http://consuper.ifc.edu.br/wp-content/uploads/sites/14/2014/07/RESOLU\% C3\%87\%C3\%83O009-2013-Normas-para-Afastamento-alterada-pelas-Resolu\%C3\%A7\%C3\%B5es-065-2013-e003-2014-JOSE.pdf. Acesso em: 03 out. 2017.

INSTITUTO FEDERAL CATARINENSE (IFC). Resolução n. 065 CONSUPER/2013. Dispõe sobre a alteração na Resolução/CONSUPER n. 009/2013, de 01/03/2013. 2013b. Disponível em: http://consuper.ifc.edu.br/wp-content/uploads/sites/14/2014/07/RESOLU\% C3\%87\%C3\%830065-2013-Aprova-altera\%C3\%A7\%C3\%B5es-na-Res.-009-2013-Normas-para-afastamento.pdf. Acesso em: 03 out. 2017.

INSTITUTO FEDERAL CATARINENSE (IFC). Resolução n. 003 CONSUPER/2014. Dispõe sobre a alteração na Resolução/CONSUPER n. 009/2013, de 01/03/2013. 2014. Disponível em: http://consuper.ifc.edu.br/wp-content/uploads/sites/14/2014/07/RESOLU\% C3\%87\%C3\%83O003-2014-Altera-Normas-para-afastamento-009-2013.pdf. Acesso em: 03 out. 2017.

INSTITUTO FEDERAL CATARINENSE (IFC). SIBI-IFC: Sistema Integrado de Bibliotecas. $2017 \mathrm{f}$. Disponível em: http://biblioteca.ifc.edu.br/. Acesso em: 13 jun. 2017.

INSTITUTO FEDERAL CATARINENSE (IFC). SIGAA: Sistema Integrado de Gestão De Atividades Acadêmicas. 2017e. Disponível em: https://sig.ifc.edu.br/sigaa/public/home.jsf. Acesso em: 01 set. 2017.

INSTITUTO FEDERAL CATARINENSE (IFC). Termo de compromisso e responsabilidade relativo à afastamento integral para pós-graduação Stricto Sensu. 2013c. Disponível em: http://manualdoservidor.ifc.edu.br/wp-content/uploads/sites/13/2014/07/TERMO-DECOMPROMISSO-AFAST.-P\%C3\%93S-GRADUA\%C3\%87\%C3\%830-1.pdf. Acesso em: 03 out. 2017.

JAMIL, G. L. Repensando a empresa moderna. Rio de Janeiro: Axcel Books, 2001.

KREMER, J. M. Information flow among engineers in a design company. 1980. $158 \mathrm{f}$. Thesis (Doctor of Philosophy in Library Science) - School of Library Science, University of Illinois, Urbana, 1980.

KROEFF, M. S. et al. Análise de citações dos artigos publicados em periódicos da área da Ciência da Informação que versam sobre gestão da informação. RBBD: Revista Brasileira de Biblioteconomia e Documentação, São Paulo, v. 11, n. 1, p. 41-65, jul. 2015. Disponível em: https://rbbd.febab.org.br/rbbd/article/view/301/397. Acesso em: 06 jun. 2017.

LE COADIC, Y.-F. A ciência da informação. 2. ed. Brasília, DF: Briquet de Lemos, 2004. 
LEITÃO, D. M. A informação: insumo e produto do desenvolvimento tecnológico. Ciência da Informação, Brasília, DF, v. 14, n. 2, p.93-107, jul./dez., 1985.

LEITE, F. C. L.; COSTA, S. M. de S. Modelo genérico de gestão da informação científica para instituições de pesquisa na perspectiva da comunicação científica e do acesso aberto. Investigación Bibliotecológica: Archivonomía, Bibliotecología e Información, v. 30, n. 69, Supplement, p. 41-71, may./aug. 2016.

LESCA, H.; ALMEIDA, F. C. de. Administração Estratégica da Informação. Revista de Administração da FEA/USP, v. 29, n. 3, p. 66-75, jul./set. 1994. Disponível em: https://www.researchgate.net/publication/255623678 ADMINISTRACAO ESTRATEGICA DA I NFORMACAO. Acesso em: 8 jun. 2017.

LOPES, A. L. Integração do mecanismo de sincronização PTCRISync com o CRIS do ISCTE-IUL. Revista Eletrônica de Comunicação, Informação \& Inovação em Saúde, Rio de Janeiro, v. 11, dec. 2017.

MARCOLINO, A. A contribuição do mapeamento do fluxo de informações para o planejamento de sistemas de informação de apoio à decisão estratégica: um estudo de caso na Embrapa solos. 2015. 114f. Dissertação (Mestrado em Ciência da Informação) - Programa de Pós-graduação em Ciência da Informação, Escola de Comunicação, Instituto Brasileiro de Informação em Ciência e Tecnologia, Universidade Federal do Rio de Janeiro, Rio de Janeiro, 2015. Disponível em: http://ridi.ibict.br/handle/123456789/785. Acesso em: 12 dez. 2017.

MARTÍNEZ-SILVEIRA, M.; ODDONE, N. Necessidades e comportamento informacional: conceituação e modelos. Ciência da Informação, Brasília, v. 36, n. 2, p. 118-127, maio/ago. 2007.

MEADOWS, A. J. A comunicação científica. Brasília: Briquet de Lemos, 1999. 268 p.

MELO, B. K. da S. B. de. Fluxo da comunicação científica na área de Ciência da Informação no Brasil: análise da produção científica relacionada com teses defendidas de 2008 a 2010. 2014. 144 f.: il. Monografia (Graduação em Biblioteconomia) - Universidade de Brasília, Faculdade de Ciência da Informação, Curso de Graduação em Biblioteconomia, Brasília, DF, 2014.

MINISTÉRIO DA EDUCAÇÃO. PDA-MEC 2016/2018 Plano de Dados Abertos do MEC para o biênio. 2016. Disponível em: https://pdfdocumento.com/2018-dados-abertosmec 59fdaf171723dd45ffef43ba.html. Acesso em: 13 mar. 2017.

MORENO, F. P; MÁRdero ARELlANO, M. Á. M. Publicação científica em arquivos de acesso aberto. Arquivística.net, Rio de Janeiro, v.1, n.1, p.76-86 jan./jun. 2005.Disponível em: http://eprints.rclis.org/17597/. Acesso em: 28 jun. 2017.

MORESI, E. A. D. Delineando o valor do sistema de informação de uma organização. Ciência da Informação, Brasília, v. 29, n.1, p.14-24, jan./apr. 2000. Disponível em: http://www.scielo.br/pdf/ci/v29n1/v29n1a2. Acesso em: 17 ago. 2017.

MUELLER, S. P. M. A ciência, o sistema de comunicação científica e a literatura científica. In: CAMPELLO, B. S.; CENDÓN, B. V.; KREMER, J. M. (Org.). Fontes de informação para pesquisadores e profissionais. Belo Horizonte: UFMG, 2000. p. 21-34. 
NASCIMENTO, N. M. do. Tipos documentais e fluxos de informação como subsídios para o processo decisório em ambientes organizacionais. 2014. 191f. Dissertação (Mestrado em Ciência da Informação) - Faculdade de Filosofia e Ciências, Universidade Estadual Paulista, Marília, 2013. Disponível em: http://hdl.handle.net/11449/149973. Acesso em: 12 jul. 2017.

NAVARRO, C. C. Gestión de Inovatión en las organizaciones. Murcia, Spain: 2000

NORTH, K.; PRESSER, N. H. Reflexões fundamentais para a prática da gestão do conhecimento. Recife: Néctar, 2011

O'BRIEN, J. A. Sistemas de informação e as decisões gerenciais na era da Internet. 2. ed. São Paulo: Saraiva, 2004. $431 \mathrm{p}$.

OPEN KNOWLEDGE BRASIL. Introdução aos dados abertos. Disponível em: https://br.okfn.org/dados-abertos/. Acesso em: 13 mar. 2017.

OPEN RESEARCHER AND CONTRIBUTOR ID (ORCID). O que é o ORCID. 2017. Disponível em: https://orcid.org/about/what-is-orcid/mission. Acesso em: 22 fev. 2017.

PÁDUA, E. M. M. de. Metodologia da pesquisa: abordagem teórico-prática. 17. ed. Campinas (SP): Papirus, 2012. 127 p.

PETRÓ, B. Análise do fluxo informacional dos gestores turísticos da unidade de conservação Parque Natural Municipal Mata Atlântica de Atalanta, Santa Catarina. Florianópolis, 2008. 183 f. Dissertação (Mestrado em Ciência da Informação) - Programa de Pós-Graduação em Ciência da Informação, Universidade Federal de Santa Catarina, Florianópolis, 2008. Disponível em: http://www.tede.ufsc.br/teses/PCIN0034-D.pdf. Acesso em: 22 ago. 2017.

PINTO et al. Visibilidade e monitoramento científico na área nuclear e ciências relacionadas: uma perspectiva a partir da produtividade do IPEN-CNEN/SP. Perspectivas em Ciência da Informação, v.15, n.2, p.198-218, maio/ago. 2010.

RODRIGUES, C.; BLATTMANN, U. Uso das fontes de informação para a geração de conhecimento organizacional. Perspectivas em Gestão \& Conhecimento, v. 1, n. 2, 2011. Disponível em: http://periodicos.ufpb.br/index.php/pgc/article/view/9999. Acesso em: 28 jun. 2017.

SANTARÉM, V.; VITORIANO, M. C. C. P. Gestão da informação, fluxos informacionais e memória organizacional como elementos da inteligência competitiva. Perspectivas em Gestão \& $\begin{array}{lllll}\text { Conhecimento, } & \text { v. } 2016 . & \text { Disponível em: }\end{array}$ http://periodicos.ufpb.br/index.php/pgc/article/view/27387. Acesso em: 20 jun. 2017.

SANTOS, T. C. S. dos. Narrativa no fluxo de informação durante o compartilhamento de conhecimento em MPEs: um estudo multicaso nos núcleos setoriais e câmaras da ACIF. 2014. 202 f. Dissertação (Mestrado em Ciência da Informação) - Programa de Pós-Graduação em Ciência da Informação, Universidade Federal de Santa Catarina, Florianópolis, 2014 Disponível em: http://www.bu.ufsc.br/teses/PCIN0109-D.pdf. Acesso em: 11 out. 2017.

SAVI, M. G. M.; SILVA, E. L. da. O fluxo da informação na prática clínica dos médicos residentes: análise na perspectiva da medicina baseada em evidências. Ciência da Informação, Brasília, v.

Perspectivas em Gestão \& Conhecimento, João Pessoa, v. 8, n. 3, p. 127-149, set./dez. 2018. 
38, n. 3, set./dez. 2009.

SILVEIRA NETTO, R. Fluxos de informação em organizações virtuais: o caso dos estudos de impacto ambiental como produtos informacionais. 2017. 173 f. Dissertação (Mestrado em Ciência da Informação) - Programa de Pós-Graduação em Ciência da Informação, Universidade Federal de Santa Catarina, Florianópolis, 2017. Disponível em: http://www.bu.ufsc.br/teses/PCIN0156-D.pdf. Acesso em: 23 mar. 2017.

STAREC, C. A dinâmica da informação: a gestão estratégica da informação para a tomada de decisão nas organizações. In: STAREC, C.; GOMES, E.; BEZERRA, J. (Org.). Gestão estratégica da informação e inteligência competitiva. 4. tiragem rev. e atual. São Paulo: Editora Saraiva, 2006.

STARCK, K. R.; VARVAKIS, G. J.; SILVA, E. L. da. Os estilos e os modelos de gestão da informação: alternativas para a tomada de decisão. Biblios, n. 52, p. 59-73, 2013. Disponível em: http://www.revistas.usp.br/incid/article/download/69327/pdf 13. Acesso em: 1 mar. 2017.

SOARES, S. de B. C. Workshop "ORCID para autores". Semana da Pós-Graduação na EESC, 13., 2017. São Carlos: SBI. Disponível em: https://www.youtube.com/watch?v=STHuwLAhUMI. Acesso em: 17 mar. 2017.

SUGAHARA, C. R.; VERGUEIRO, W. de C. S. Fluxo de informação na perspectiva do ambiente em rede. RDBCI: Revista Digital de Biblioteconomia e Ciência da Informação, Campinas, SP, v. 11, n. 2, p. 76-97, abr. 2013. Disponível em: https://periodicos.sbu.unicamp.br/ojs/index.php/rdbci/article/view/1639. Acesso em: 08 nov. 2017.

VAlENTIM, M. L. P. Ambientes e fluxos de informação. In: VALENTIM, M. L. P. (Org.). Ambientes e fluxos de informação. São Paulo: Cultura Acadêmica, 2010. p.13-22.

VALENTIM, M. L. P. Ambientes e fluxos de informação em contextos empresariais: o caso do setor cárnico de Salamanca, Espanha. Brazilian Journal of Information Science, v. 7, n. Especial, p. 299-323, $1 . \quad$ sem. 2013. Disponível em: http://www2.marilia.unesp.br/revistas/index.php/bjis/article/view/3130. Acesso em: 11 ago. 2017.

VALENTIM, M. L. P.; TEIXEIRA, T. M. C. Fluxos de informação e linguagem em ambientes organizacionais. Informação \& Sociedade: Estudos, João Pessoa, v. 22, n. 2, p. 151-156, maio/ago. 2012. Disponível em: http://www.ies.ufpb.br/ojs/index.php/ ies/article/view/10651/7764. Acesso em: 21 jul. 2017.

VIEIRA, E. M. F. Fluxo informacional como processo à construção de modelo de avaliação para implantação de cursos em educação a distância. 2006. 183f. Tese (Doutorado em Engenharia e Gestão do Conhecimento) - Programa de Pós-Graduação em Engenharia e Gestão do Conhecimento, Universidade Federal de Santa Catarina, Florianópolis, 2006. Disponível em: https://repositorio.ufsc.br/handle/123456789/88291. Acesso em: 14 jul. 2017.

VITAL, L. P.; FLORIANI, V. M.; VARVAKIS, G. Gerenciamento do fluxo de informação como suporte ao processo de tomada de decisão. Informação \& Informação, Londrina, v. 15, n. 1, p.

Perspectivas em Gestão \& Conhecimento, João Pessoa, v. 8, n. 3, p. 127-149, set./dez. 2018. 
85-103, jun./jul. 2010. Disponível em: http://www.uel.br/revistas/uel/index.php/informacao/article/view/5335. Acesso em: 18 out. 2017.

WOIDA, L. M. Cultura informacional voltada à inteligência competitiva organizacional no setor de calçados de São Paulo. 2008. 254 f. Dissertação (Mestrado) - Faculdade de Filosofia e Ciências, Universidade Estadual Paulista, Marília, 2008. Disponível em: https://www.marilia.unesp.br/Home/Pos-

Graduacao/Cienciadalnformacao/Dissertacoes/woida Im me mar.pdf. Acesso em: 21 out. 2017.

YIN, R. K. Estudo de caso: planejamento e métodos. 5. ed. Porto Alegre: Bookman, 2015. 